\title{
Triagem sorológica e influência do conhecimento sobre a dengue em pacientes do ambulatório de especialidades do SUS
}

\author{
Serological screening and the influence of dengue awareness on patients from SUS specialty laboratory \\ Viviane Aparecida Vilas Boas'; Katya Cristina Rocha²; Claudia Giorgia Bronzatti de Oliveira ${ }^{3}$; Aleksandra Vanessa Lambiasi Sant'Anna4; \\ Ligia Ajaime Azzalis ${ }^{5}$; Registila Libânia Beltrame ${ }^{6}$; Virginia Berlanga Campos Junqueira ${ }^{7}$; Fernando Luiz Affonso Fonseca ${ }^{8}$
}

unitermos
Dengue
Aedes aegypti
Região do Grande ABC

\section{resumo}

Introdução: A dengue é causa de preocupação em países como o Brasil. Objetivo: Verificar a soropositividade dos pacientes do ambulatório de especialidades do Sistema Único de Saúde (SUS) para anticorpos antidengue, relacionando os resultados com os dados sociodemográficos. Metodologia: Foram respondidos 184 questionários de avaliação sociodemográfica e de conhecimento sobre a transmissão da dengue. Foi utilizado o método de imunoensaio enzimático (ELISA) para pesquisar imunoglobulina da classe M ( $\operatorname{lgM})$ e da classe G ( $\mathrm{lgG}$ ) contra os vírus. Resultados: Quinze por cento dos pacientes apresentaram $\lg G$ contra o vírus, sem a presença de $\lg M$. Conclusão: Os pacientes demonstraram conhecimento sobre a doença e sua prevenção, independentemente da classe econômica. A infecção assintomática deve ser avaliada, principalmente nos casos de doença febril.

\section{abstract}

Introduction: Dengue is a public health problem in Brazil and worldwide. Objective: To determine dengue seropositivity of patients from SUS specialty laboratory by correlating the results with socio-demographic data. Methods: One hundred and eighty-four questionnaires on socio-demographic assessment and dengue transmission awareness were filled out. Enzyme linked immunosorbent assay (ELISA) method was performed for the detection of IgM and Ig G antibodies against dengue virus. Results: Fifteen percent of patients had IgG against dengue virus without the presence of IgM. Conclusion: All patients showed disease and prevention awareness regardless of their socio-economic background. The asymptomatic infection must be evaluated mainly in cases of disease with fever.

\section{key words}

Dengue

Aedes aegypti

$A B C$ region

1. Mestranda do programa de pós-graduação em Ciências da Saúde da Faculdade de Medicina do ABC (FMABC).

2. Doutora em Ciências da Saúde pela Faculdade de Medicina da Universidade de São Paulo (FMUSP); professora assistente da disciplina de Microbiologia e Imunologia da FMABC.

3. Mestra em Ciências da Saúde pela FMUSP; bióloga do Laboratório de Análises Clínicas da FMABC.

4. Mestra em Ciências da Saúde pela FMUSP; bióloga do Laboratório de Análises Clínicas da FMABC.

5. Doutora em Bioquímica pelo Instituto de Química (IQ) da USP; professora adjunta do Departamento de Ciências Exatas e da Terra da Universidade Federal de São Paulo (UNIFESP)-Diadema. 6. Doutora em Educação pela Pontifícia Universidade Católica de São Paulo (PUC-SP); professora titular da disciplina de Microbiologia e Imunologia da FMABC.

7. Livre-docente em Bioquímica pelo IQUSP; professora titular do Departamento de Ciências Biológicas da UNIFESP-Diadema.

8. Pós-doutor em Ciências da Saúde pela Roche Center for Medical Cenomics; professor adjunto do Departamento de Ciências Biológicas da UNIFESP-Diadema; professor assistente do curso de Ciências Farmacêuticas da FMABC. 


\section{Introdução}

A dengue representa um relevante problema de saúde pública no Brasil( ${ }^{(11)}$. Foi com a extensa epidemia de 1986 no Rio de Janeiro e a disseminação para regiões vizinhas que as ações de vigilância e controle dos vetores da dengue tornaram-se prementes no Brasil(4).

A dengue é uma doença que se manifesta como uma enfermidade infecciosa aguda caracterizada por um amplo espectro clínico que varia desde formas de infecção assintomática ou febre indiferenciada até as formas graves com hemorragia e/ou choque ${ }^{(17)}$. É conhecida como "febre quebra ossos", devido à prostração e à artralgia intensas. Sua forma clínica mais frequente é a forma inaparente ou assintomática. Existem três formas clínicas: dengue assintomática, dengue clássica e dengue hemorrágica ou síndrome de choque da dengue ${ }^{(10)}$. A dengue não tem tratamento específico. A medida terapêutica mais importante é a hidratação, por via oral ou por via intravenosa nos casos mais graves.

A ocorrência da dengue no Brasil pode ser considerada decorrente da reinfestação do território nacional pelo vetor Aedes aegypti( ${ }^{(8)}$. É uma espécie de mosquito da família Culicidae, proveniente da África, atualmente distribuído por quase todo o mundo, com ocorrência nas regiões tropicais e subtropicais, sendo dependente da concentração humana no local para se estabelecer. O mosquito está bem adaptado a zonas urbanas, mais precisamente ao domicílio humano, onde consegue se reproduzir e pôr seus ovos em pequenas quantidades de água limpa, ou seja, pobres em matéria orgânica em decomposição e sais, o que as concede características ácidas, que preferivelmente estejam sombreados e no peridomicílio(1). Seu controle é difícil, por ser muito versátil na escolha dos criadouros onde deposita seus ovos, que são extremamente resistentes, podendo sobreviver vários meses até que a chegada de água propicie a incubação(7).

Sabe-se, hoje, que o agente etiológico da dengue é representado por um complexo de quatro sorotipos de vírus da família Flaviviridae, gênero Flavivirus, todos causando a mesma síndrome clínica. São eles: dengue-1 (DEN-1), dengue-2 (DEN-2), dengue-3 (DEN-3) e dengue-4 (DEN-4). Cada um desses sorotipos possui várias cepas diferentes difundidas na mesma região ou em diversas partes do mundo ${ }^{(17)}$.

A resposta humoral contra o vírus costuma ser vigorosa. Os anticorpos específicos da imunoglobulina da classe $\mathrm{M}$ (IgM) são detectáveis a partir do quarto dia após o início dos sintomas, atingindo os níveis mais elevados por volta do sétimo ou oitavo dia, declinando lentamente, passando a não serem detectáveis após alguns meses. As imunoglobulinas da classe G (IgGs) específicas são observadas em níveis baixos a partir do quarto dia após o início dos sintomas, elevam-se atingindo altos teores em duas semanas e mantêm-se detectáveis por vários anos, conferindo imunidade contra o tipo infectante provavelmente por toda a vida. Anticorpos obtidos durante a infecção por um determinado sorotipo de vírus da dengue protegem da infecção por outros sorotipos homólogos, porém essa proteção é de curta duração, aproximadamente dois a três meses ${ }^{(17,18)}$.

Algumas variantes genéticas em cada sorotipo parecem ser mais virulentas ou ter maior potencial epidêmico ${ }^{(12,19)}$. A circulação simultânea de diferentes sorotipos demonstra que infecções sucessivas aumentam o aparecimento de formas clínicas mais graves, como foi evidenciado pela presença de formas hemorrágicas após a introdução do DEN-2. Assim, a introdução de novos sorotipos do vírus da dengue no Brasil eleva o risco de aparecimento das formas clínicas mais graves da doença ${ }^{(15)}$.

Como a dengue tem uma apresentação clínica muito polimorfa, o diagnóstico laboratorial é muito importante para confirmar a suspeita ${ }^{(14)}$. Os testes sorológicos são os mais amplamente utilizados para a detecção da infecção pelo vírus da dengue. A técnica de imunoensaio enzimático (ELISA) é usada para detectar anticorpos da classe IgM e IgG contra a dengue em amostras de soro ou plasma por meio da enzima que atua como marcador. É o exame mais útil para vigilância, pois é simples e rápido. A técnica de hemaglutinação utiliza partículas de gelatina ou látex que são sensibilizadas com vírus inativado, baseando-se no princípio de que as partículas sensibilizadas se aglutinam na presença de anticorpos dirigidos contra epítopos do vírus da dengue presentes no soro ou plasma do indivíduo. Já a detecção do vírus (carga viral) por meio de seu material genético, utilizada para a avaliação dos sorotipos, deve ser feita, de preferência, no período da viremia durante a primeira semana de infecção. Uma das técnicas utilizadas é a reação de polimerase em cadeia (PCR), utilizando a transcriptase reversa (RT), pois, nesse caso, são utilizados primers específicos capazes de permitir a amplificação exclusiva de DEN-1, DEN-2, DEN-3 ou DEN-4(6).

Existem várias outras técnicas que também podem ser utilizadas no diagnóstico sorológico do vírus da dengue como fixação de complemento ( $\mathrm{FC})$ e neutralização $(\mathrm{N})$. No entanto, nenhum desses testes identifica o sorotipo envolvido ${ }^{(14)}$. 
Os países tropicais são os mais atingidos pela doença em função de suas características ambientais, climáticas e sociais ${ }^{(7)}$. Porém, a incidência de casos de dengue também flutua com as condições climáticas e está associada a aumento da temperatura, pluviosidade e umidade do ar, condições que favorecem a elevação do número de criadouros disponíveis e o desenvolvimento do vetor ${ }^{(3)}$.

O processo de urbanização desordenado com grande aglomeração populacional, as deficiências no suprimento de água, o tratamento de esgoto inexistente ou inadequado e a ausência de destino adequado do lixo com o acúmulo de recipientes plásticos não biodegradáveis contribuem para essa situação. Além disso, a facilidade de transporte e as intensas relações comerciais entre regiões, permitindo a entrada de pessoas infectadas em período de incubação ou mesmo do vetor em localidades indenes, e a falência dos programas de controle do mosquito favorecem o aumento da transmissão do dengue ${ }^{(16)}$. Essa situação também é encontrada na região do Grande $A B C$, onde todas as características citadas estão presentes e condicionam o aparecimento da doença.

Segundo dados do Ministério da Saúde, entre janeiro e setembro de 2006 foram registrados 279.241 casos de dengue, o equivalente a um caso (não fatal) para cada $30 \mathrm{~km}^{2}$ do território do país. Isso indica um crescimento de $26,3 \%$ em relação ao mesmo período em 2005 , sendo a maior incidência na região Sudeste do Brasil.

Em 1985, a Superintendência de Controle de Endemias (SUCEN) realizou um levantamento entomológico abrangendo todas as cidades paulistas, tendo sido detectados focos de Aedes aegypti em 30 municípios, localizados, principalmente, no oeste paulista(20).

Entre 1986 e 1996, verificou-se contínua, rápida e ampla dispersão do Aedes aegypti, ocupando as regiões Oeste, Norte e Central do estado. Em 1995, o número de municípios que apresentavam infestação pela espécie era de 416, distribuídos em áreas nas quais residiam aproximadamente 8 milhões de pessoas. Desde então, a expansão geográfica desse vetor continua ocorrendo, sendo que, em 2001, o número de municípios no qual o Aedes aegypti estava presente totalizou 481.

A transmissão da dengue no estado de São Paulo teve início em 1985 e desde então vem apresentando tendência de crescimento/ascensão; em 2001 foram confirmados 51.472 casos, configurando-se como a maior incidência de dengue já observada ${ }^{(22)}$. De acordo com a Organização Mundial da Saúde (OMS), o Brasil é o país, em todo o mundo, que apresenta o maior número de casos de febre da dengue (dengue clássica, assintomática e hemorrágica). Ser o primeiro país no ranking internacional significa que o Brasil detém 71\% dos casos notificados nas Américas e $61 \%$ dos notificados em todo o mundo. Os levantamentos realizados pela OMS demonstram que os casos encontrados no Brasil não só estão em maior número que os observados na Ásia como acometem populações com idades distintas; na Ásia, observa-se o predomínio dos casos em crianças, já no Brasil a doença predomina em adultos ${ }^{(21)}$. Considerando-se o contínuo aumento do número de municípios infestados pelo Aedes aegypti, associado ao fato indicador de que a região do Grande $A B C$ possui as condições adequadas para a proliferação do mosquito, parece-nos relevante a identificação de casos de infecção inaparente pelo vírus da dengue, uma vez que a presença de anticorpos contra esse vírus pode predispor ao desenvolvimento das formas mais graves de dengue (dengue hemorrágica e síndrome do choque da dengue).

\section{Objetivo}

O objetivo deste estudo foi avaliar, por meio de triagem sorológica para o vírus da dengue, a presença de anticorpos contra o vírus no soro dos pacientes encaminhados ao ambulatório de especialidades do Sistema Único de Saúde (SUS) na Faculdade de Medicina do ABC (FMABC) que, em sua história pregressa, não apresentam evidências/diagnóstico de febre da dengue. Além do estudo sorológico, o perfil sociodemográfico desses indivíduos e o conhecimento deles acerca da transmissão da dengue e do controle do vetor foram investigados.

\section{Método}

\section{Casuística}

Pacientes de ambos os sexos, maiores de 18 anos, encaminhados ao ambulatório de especialidades do SUS na FMABC, no período de janeiro a maio de 2007, foram avaliados por meio de um questionário quanto ao perfil sociodemográfico e ao conhecimento sobre as formas de prevenção da dengue. Após responderem às perguntas, os pacientes interessados ( 93 no total) assinaram um termo de consentimento para a coleta de amostra de sangue periférico e realização da sorologia para pesquisa de anticorpos contra o vírus da dengue. A coleta de sangue foi realizada por punção venosa no serviço de coleta do Laboratório de Análises Clínicas da FMABC. O sistema utilizado foi 
operado em condições de vácuo com tubo siliconizado (sem anticoagulante).

\section{Ensaio sorológico para determinação de anticorpos IgM e IgG contra o vírus da dengue}

A pesquisa de anticorpos em amostras de soro dos indivíduos que aderiram à pesquisa foi realizada com o uso do método ELISA. Foram determinados os anticorpos da classe $\lg \mathrm{M}$ e $\lg \mathrm{G}$ contra o vírus da dengue por meio de ensaio tipo sanduíche (Human do Brasil - 196 testes, lote H024, validade $09 / 2007$, conservado entre $+2 \mathrm{e}+8^{\circ} \mathrm{C}$; Human do Brasil -196 testes, lote $\mathrm{H} 019$, validade $03 / 2008$, conservado entre $+2 \mathrm{e}+8^{\circ} \mathrm{C}$, respectivamente). A leitura dos ensaios foi realizada com o uso de equipamento do tipo leitora de ELISA Hyperion e os resultados foram expressos em unidades de anticorpos $/ \mathrm{ml}$. Amostras que apresentaram $11 \mathrm{U} / \mathrm{ml}$ ou mais para anticorpos $\lg \mathrm{M}$ ou $\lg \mathrm{G}$ foram consideradas positivas.

\section{Análise estatística}

Para a análise estatística foi utilizado o teste de Fisher com o auxílio do aplicativo SSP.

\section{Resultados}

\section{Característica sociodemográfica da população estudada}

Dos pacientes avaliados (189 no total), apenas 93 concordaram em realizar o exame sorológico para pesquisa de anticorpos contra o vírus da dengue e responderam ao questionário sociodemográfico (Tabela 1). A idade média desses indivíduos foi de 45 anos. Quanto ao sexo, houve uma participação significativamente maior de mulheres (71\%) do que homens (29\%).

Com relação à distribuição dos municípios de origem, temos: $53 \%$ do total residiam em Santo André, 17\% em São Bernardo do Campo, 13\% em Diadema e 11\% em Mauá. A menor população foi a de Rio Grande da Serra (1\%), na qual apenas 3\% residiam fora da região do Grande $A B C$, sendo todos esses moradores da cidade de São Paulo.

Cerca de $63 \%$ dos participantes afirmaram ser de etnia branca, $24 \%$ de etnia parda, $11 \%$ de etnia negra e $2 \%$ de etnia amarela. Quanto ao estado civil, $58 \%$ eram casados, $26 \%$ eram solteiros, $10 \%$ eram viúvos e $6 \%$ eram divorciados.

Quanto à quantidade de pessoas que moravam na mesma casa que o paciente, a maioria $(47,31 \%)$ respondeu que residia com quatro a cinco pessoas; $7,5 \%$ moravam sozinhos, sendo, na maioria das vezes, viúvos.

Cerca de 55\% dos pacientes afirmaram não trabalhar. Dos empregados, $80 \%$ trabalhavam no setor de serviços, sendo, em sua maioria, comerciantes e vendedores; $20 \%$ trabalhavam no setor industrial e nenhum dos participantes atuava no setor agropecuário.

No que se refere ao nível educacional, 29\% não haviam concluído o ensino fundamental, $24,73 \%$ concluíram o ensino médio e a minoria concluiu o ensino superior ou possuía o ensino médio incompleto.

Quanto à renda total da casa, $45 \%$ dos participantes tinham renda mensal de dois a três salários mínimos, seguidos de $26 \%$ com renda de quatro a cinco salários mínimos; $6 \%$ responderam ter renda mensal superior a cinco salários mínimos.

\section{Conhecimento acerca da transmissão da dengue e medidas tomadas pela população estudada para evitar a proliferação do vetor}

A primeira pergunta do questionário aplicado tinha o objetivo de verificar o conhecimento dos participantes quanto ao fato de a dengue ser transmitida por um mosquito (Tabela 2). Quase todos os participantes (99\%) tinham esse conhecimento.

Quando perguntados se tentavam de alguma forma evitar a transmissão da doença, $96 \%$ dos participantes responderam que tomavam algum tipo de atitude para evitar a transmissão da doença e a proliferação do mosquito. Desses, $24 \%$ responderam que evitavam exposição de pneus e garrafas em áreas descobertas, $25 \%$ mantinham a caixa d'água fechada, $14 \%$ não deixavam água parada em bebedouros de animais e $21 \%$ colocavam areia/cascalho em vasos sanitários. Dos pacientes que relataram tomar alguma medida preventiva contra a dengue, $26 \%$ afirmaram realizar todas as ações preventivas recomendadas e $4 \%$ não realizavam nenhuma dessas ações.

Ao serem questionados se já haviam recebido visitas de agentes de saúde em suas casas, $65 \%$ responderam que sim; $35 \%$ nunca tinham recebido qualquer visita de agentes de saúde.

Quando perguntados se já haviam tido alguma vez um quadro clínico suspeito para dengue, apenas $6 \%$ dos pacientes responderam afirmativamente. Quando questionados se já haviam realizado exames para o diagnóstico de dengue, apenas $3 \%$ confirmaram, tendo esse dado sido descartado. 


\section{Características sociodemográficas da população atendida no laboratório de análises clínicas da}

Tabela 1 Faculdade de Medicina do ABC

\begin{tabular}{|c|c|c|c|c|c|c|c|}
\hline Sexo & $\begin{array}{c}\text { Feminino } \\
71 \%\end{array}$ & $\begin{array}{c}\text { Masculino } \\
29 \%\end{array}$ & & & & & \\
\hline $\begin{array}{l}\text { Cidade } \\
\text { de origem }\end{array}$ & $\begin{array}{c}\text { Santo André } \\
53 \%\end{array}$ & $\begin{array}{c}\text { São } \\
\text { Bernardo } \\
17 \%\end{array}$ & $\begin{array}{c}\text { Diadema } \\
13 \%\end{array}$ & $\begin{array}{c}\text { Rio Grande } \\
\text { da Serra } \\
1 \%\end{array}$ & $\begin{array}{l}\text { Mauá } \\
11 \%\end{array}$ & $\begin{array}{c}\text { Outros } \\
3 \%\end{array}$ & \\
\hline Etnia & $\begin{array}{c}\text { Branca } \\
63 \%\end{array}$ & $\begin{array}{c}\text { Parda } \\
24 \%\end{array}$ & $\begin{array}{c}\text { Negra } \\
11 \%\end{array}$ & $\begin{array}{c}\text { Amarela } \\
2 \%\end{array}$ & & & \\
\hline Estado civil & $\begin{array}{c}\text { Casado } \\
58 \%\end{array}$ & $\begin{array}{c}\text { Solteiro } \\
26 \%\end{array}$ & $\begin{array}{c}\text { Divorciado } \\
6 \%\end{array}$ & $\begin{array}{l}\text { Viúvo } \\
10 \%\end{array}$ & & & \\
\hline $\begin{array}{l}\text { Número } \\
\text { de pessoas } \\
\text { na casa }\end{array}$ & $\begin{array}{l}0-1- \\
7,5 \%\end{array}$ & $\begin{array}{c}2-3- \\
22,5 \%\end{array}$ & $\begin{array}{c}4-5- \\
47,31 \%\end{array}$ & $\begin{array}{c}>5- \\
20,43 \%\end{array}$ & & & \\
\hline $\begin{array}{l}\text { Nível } \\
\text { de ensino }\end{array}$ & $\begin{array}{c}\text { Sem } \\
\text { instrução } \\
12,9 \%\end{array}$ & $\begin{array}{c}\text { Ensino } \\
\text { fundamental } \\
\text { incompleto } \\
29 \%\end{array}$ & $\begin{array}{c}\text { Ensino } \\
\text { fundamental } \\
\text { completo } \\
13,9 \%\end{array}$ & $\begin{array}{c}\text { Ensino médio } \\
\text { incompleto } \\
6,45 \%\end{array}$ & $\begin{array}{l}\text { Ensino } \\
\text { médio } \\
\text { completo } \\
24,73 \%\end{array}$ & $\begin{array}{c}\text { Ensino } \\
\text { superior } \\
\text { incompleto } \\
5,3 \%\end{array}$ & $\begin{array}{l}\text { Ensino } \\
\text { superior } \\
\text { completo } \\
7,5 \%\end{array}$ \\
\hline Renda & $\begin{array}{c}\text { Até } 1 \text { salário } \\
\text { 13,97\% }\end{array}$ & $\begin{array}{c}2 \text { a } 3 \\
\text { salários } \\
45,16 \%\end{array}$ & $\begin{array}{c}3 \text { a } 4 \\
\text { salários } \\
30,1 \%\end{array}$ & $\begin{array}{c}\text { Mais de } 4 \\
\text { salários } \\
8,6 \%\end{array}$ & & & \\
\hline $\begin{array}{l}\text { Tipo de } \\
\text { trabalho }\end{array}$ & $\begin{array}{c}\text { Não trabalha } \\
55 \%\end{array}$ & $\begin{array}{c}\text { Trabalha no } \\
\text { comércio } \\
36 \%\end{array}$ & $\begin{array}{c}\text { Trabalha na } \\
\text { indústria } \\
9 \%\end{array}$ & $\begin{array}{c}\text { Trabalha no setor } \\
\text { agropecuário } \\
0 \%\end{array}$ & & & \\
\hline
\end{tabular}

\section{Tabela 2 Conhecimento acerca da transmissão da dengue e medidas tomadas pela população estudada}

Perguntas realizadas (93 entrevistados)

Conhece a forma de transmissão da dengue?

Previne a dengue de alguma maneira?

Fecha os vasos sanitários?

Coloca areia ou cascalho em vasos de plantas?

Evita água limpa em bebedouro de animais?

Mantém caixa d'água fechada?

Evita pneus e garrafas em áreas descobertas?

Já recebeu visita de agentes de saúde?

Já teve suspeita de dengue?

Já realizou exame para diagnóstico da dengue?

Costuma viajar para o litoral paulista?

\begin{tabular}{cc} 
Sim & Não \\
$99 \%$ & $1 \%$ \\
$96 \%$ & $4 \%$ \\
$56 \%$ & $44 \%$ \\
$21 \%$ & $79 \%$ \\
$14 \%$ & $86 \%$ \\
$25 \%$ & $75 \%$ \\
$24 \%$ & $76 \%$ \\
$65 \%$ & $35 \%$ \\
$6 \%$ & $94 \%$ \\
$3 \%$ & $97 \%$ \\
$35 \%$ & $65 \%$ \\
\hline
\end{tabular}


Como no ano de 2007 houve uma grande epidemia de dengue no litoral de São Paulo, foi perguntado aos participantes da pesquisa se eles costumavam ir à praia com frequência. A maioria dos pacientes (65\%) negou.

\section{Triagem sorológica para anticorpos contra o vírus da dengue}

Os pacientes interessados em realizar a triagem sorológica contra o vírus da dengue assinaram um termo de consentimento após terem respondido aos questionários (resultados apresentados nas Tabelas 1 e 2), autorizando a coleta de amostra biológica e realização da sorologia específica. No total foram obtidas 93 amostras. A partir dessas amostras, foram realizados os testes para pesquisa de anticorpos das classes lgM e lgG. A Figura 1 mostra o resultado da sorologia para pesquisa de anticorpo IgM. Pode-se observar que todas as amostras avaliadas foram negativas ou se encontravam abaixo do limite de detecção do método para a presença de anticorpos IgM contra o vírus da dengue.

Quanto à pesquisa de anticorpos lgG contra o vírus da dengue, $15 \%$ das amostras avaliadas foram positivas; os outros $85 \%$ de indivíduos avaliados eram negativos ou possuíam anticorpos lgG em limites inferiores ao de detecção do método empregado. A seguir, na Figura 2, é mostrada a distribuição do resultado da sorologia para a pesquisa de anticorpos $\lg G$ no soro dos participantes da pesquisa.

Dos 14 pacientes que foram positivos para a presença de anticorpos $\lg \mathrm{G}$ contra o vírus da dengue, um já havia realizado o exame anteriormente, dois tiveram suspeita de quadro de dengue clássica, quatro costumavam viajar com frequência para o litoral, mas nunca tiveram suspeita de dengue clássica ou realizaram sorologia, e sete nunca tiveram suspeita de dengue ou fizeram sorologia e não costumam viajar para o litoral.

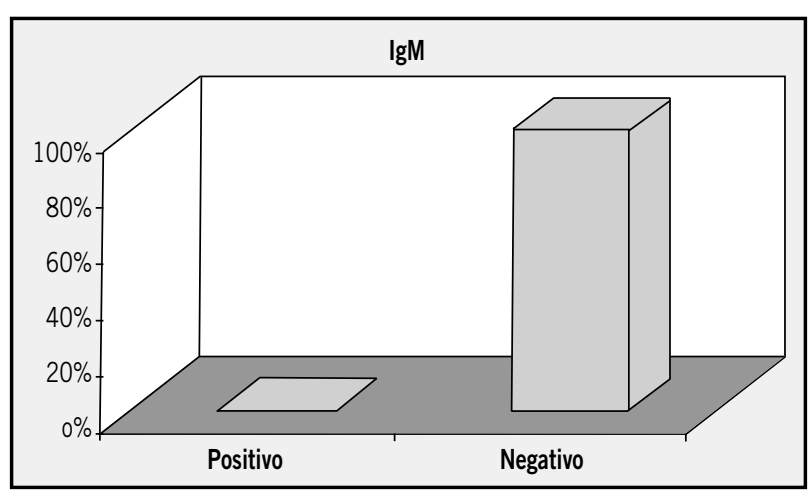

Figura 1 - Distribuição dos pacientes em relação à presença de anticorpos IgM IgM: imunoglobulina da classe $M$.

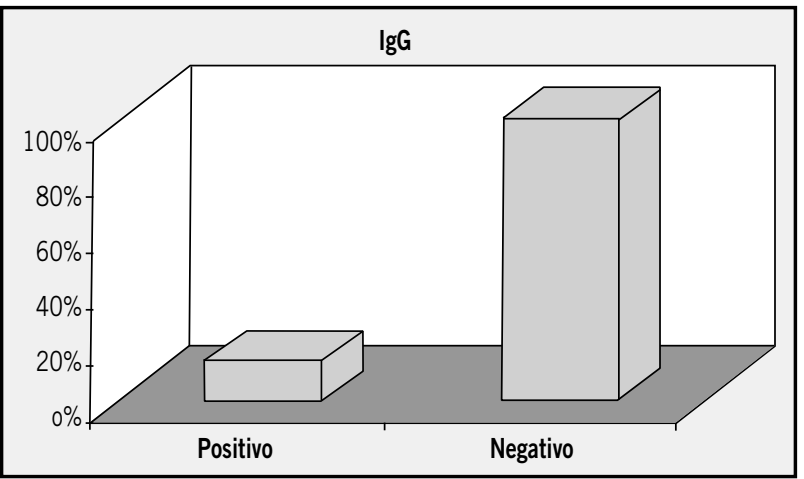

Figura 2 - Distribuição dos pacientes em relação à presença de anticorpos IgG IgG: imunoglobulina da classe $G$.

Foram realizadas análises estatísticas para avaliar a existência de correlação entre a positividade para anticorpos IgG e a cidade de origem do paciente. Nenhuma correlação foi estabelecida; da mesma maneira, foi investigada a positividade do teste para anticorpos $\lg \mathrm{G}$ e a tomada de medidas preventivas recomendadas para o controle do vetor. Novamente nenhuma correlação foi observada.

\section{Discussão}

Comparando os dados socioeconômicos obtidos nesta pesquisa com os de outro trabalho realizado pelo próprio Laboratório de Análises Clínicas da FMABC em fevereiro de $2004^{(9)}$, podemos observar que não houve diferença significativa no quadro socioeconômico dos pacientes frequentadores do Laboratório.

Em 2004, a idade média dos pacientes era de 50 anos; hoje, é de 45 anos. A taxa de analfabetismo diminuiu 4\% nesses três anos, sendo, hoje, $10 \%$ do total de pacientes. Em média, os participantes são mulheres, casadas, de etnia branca, com filhos, que não trabalham, têm ensino fundamental incompleto, moram com quatro a cinco pessoas e possuem renda mensal de dois a três salários mínimos.

Porém, se compararmos esses dados com o perfil socioeconômico dos pacientes soropositivos para a dengue, notam-se diferenças. Entre esses indivíduos, a média de idade é de 54 anos e a taxa de analfabetismo é de $21 \%$ (11\% maior que a média total).

Resumidamente, o perfil socioeconômico dos pacientes soropositivos, em sua maioria, é composto de mulheres, casadas, de etnia parda, com filhos, não trabalham, possuem ensino médio completo, moram com quatro a cinco pessoas e possuem renda mensal de três a cinco salários mínimos. Alguns autores comentam que uma das explicações para esse tipo de perfil é que as mulheres casadas, com filhos e 
que não trabalham permanecem mais tempo no intradomicílio ou peridomicílio, locais onde predominantemente ocorre a transmissão de dengue ${ }^{(22)}$.

Quase todos os pacientes têm o conhecimento de que a dengue é transmitida por um mosquito, e a maioria toma algum tipo de atitude para evitar sua proliferação. Os indivíduos avaliados tomam, no máximo, dois tipos diferentes de atitudes preventivas para evitar a transmissão da doença, sendo que o ato de fechar as caixas d'água e evitar o acúmulo de pneus e garrafas em lugares descobertos são as duas atitudes mais frequentes. Isso pode ser um reflexo do fato de que $35 \%$ dos pacientes nunca receberam uma visita de agentes de saúde em suas casas, o que, se realizado, poderia orientá-los para uma melhor prevenção quanto à proliferação e ao crescimento do mosquito, podendo prevenir, mais eficazmente, a transmissão da doença.

Quanto às sorologias, nenhum paciente foi positivo para a pesquisa de anticorpos $\operatorname{lgM}$. Tendo em mente que a presença de IgM sinaliza contato recente com o vírus da dengue e que pode determinar tanto uma infecção ativa (com sintomas clínicos) como inaparente, os resultados sugerem que todos os participantes avaliados não tenham entrado em contato recente com o vírus da dengue. Vale lembrar que em indivíduos infectados com o vírus e portadores de síndrome febril não identificada apresentaram resultados negativos para IgM e pesquisa positiva do genoma viral (realizada por meio de ensaio de reação em cadeia da polimerase (PCR), sugerindo que, mesmo diante de ensaios negativos para lgM, não se pode descartar a infecção pelo vírus ${ }^{(13)}$.

Na pesquisa de anticorpos Ig $G$ contra o vírus do dengue, $15 \%$ das amostras foram positivas. Esse resultado também é verificado por Lima et al. ${ }^{(11)}$ em Campinas, que tem condições climáticas, demográficas e socioeconômicas muito semelhantes às dos municípios do $A B C$, em que 14,79\% dos habitantes são soropositivos para o vírus do dengue.

Entretanto, apenas 4\% (do total de indivíduos avaliados) disseram já terem feito sorologia para dengue alguma vez e 5\% afirmaram já terem tido suspeita clínica para dengue. Dos $15 \%$ que foram positivos para a presença de anticorpos IgG contra o vírus da dengue, apenas três pacientes já haviam realizado o exame anteriormente ou tiveram suspeita de quadro de dengue clássica e sete pacientes ( $50 \%$ dos positivos) nunca tiveram suspeita de dengue ou fizeram sorologia. Vale ressaltar que o teste sorológico empregado, segundo o fabricante, apresenta especificidade sorológica de $94,1 \%$ e sensibilidade de $89,3 \%$. Assim, acreditamos que o número de pacientes com sorologia positiva para anticorpos lgG possa ser ainda maior do que foi por nós identificado. É certo que reações cruzadas para outros flavivírus (vírus da febre amarela, da encefalite japonesa e da encefalite de St. Louis) também são possíveis (cerca de $6 \%$ das amostras avaliadas segundo o teste empregado), sendo, portanto, necessária a confirmação da sorologia com outro tipo de ensaio(2).

Se somente $5 \%$ dos pacientes já tiveram suspeita clínica para a dengue, mas $15 \%$ desses são soropositivos, podese afirmar que pelo menos $10 \%$ da população estudada desconhecem o fato de ter tido um primeiro contato com o vírus da dengue, ou seja, desconhecem que já tiveram a doença ou a tiveram na forma subclínica. Essa observação pode tanto aumentar a suscetibilidade à reinfecção pelo vírus da dengue como levar ao desencadeamento de formas mais agressivas da doença.

De acordo com o proposto por Marzochi ${ }^{(13)}$, é fundamental que se dê mais atenção aos quadros de doença febril indiferenciada, a fim de se descartarem quadros inespecíficos de dengue, particularmente em períodos interepidêmicos ou de transmissão esporádica. Conforme observado por Watthanaworawit et al. ${ }^{(23)}$, para que uma síndrome febril possa ser descartada ou confirmada como infecção aguda pelo vírus da dengue, é necessário que se utilizem, pelo menos, dois métodos concomitantes: o método de PCR Real Time e a detecção de anticorpo lgM contra o vírus ou a detecção do antígeno viral (NS1) em combinação com a detecção de anticorpos lgM. Segundo os autores, a simples detecção de anticorpos IgM contra o vírus não é suficientemente específica e sensível para confirmar ou descartar o diagnóstico de dengue. De acordo com o que se observa atualmente, a pesquisa da presença do antígeno NS1 é fundamental para que se possa atingir elevada especificidade e sensibilidade com testes sorológicos que visem ao diagnóstico de doença aguda provocada pela infecção com o vírus da dengue ${ }^{(5)}$.

Em nosso estudo, não pudemos estabelecer qualquer associação entre a positividade para anticorpos contra o vírus da dengue e a cidade de origem do paciente. Acreditamos que para tal avaliação o número de investigados foi insuficiente, uma vez que apenas um centro da região do Grande $A B C$ foi avaliado e $53 \%$ dos participantes eram oriundos de Santo André.

Nossos resultados sugerem que há falta de informação por parte da população e que talvez haja uma subnotificação dos resultados para dengue, além da constatação da ausência de visitas de agentes comunitários que poderiam atuar de maneira mais contundente por meio de um programa de educação continuada, a fim de evitar epidemias da doença em períodos específicos durante o ano. 


\section{Referências}

1. COSOLINI, R. A. G. B.; OLIVEIRA, R. L. Principais mosquitos de importância sanitária no Brasil. Rio de Janeiro: Fundação Instituto Oswaldo Cruz, 1994.

2. De PAULA, S. O.; FONSECA, B. A. L. Dengue: a review of the laboratory tests a clinician must know to achieve a correct diagnosis. Brz J Infect Dis, v. 8, p. 390-8, 2004.

3. DEPRADINE, C. A.; LOVELL, E. H. Climatological variables and the incidence of dengue fever in Barbados. Environ Health, v. 429, n. 14, p. 41, 2004.

4. DONALÍSIO, M. R.; GLASSER, C. M. Vigilância entomológica e controle de vetores do dengue. Revista Brasileira de Epidemiologia, v. 5, n. 3, p. 259-72, 2002.

5. DUSSAR, P. et al. Evaluation of two new commercial tests for the diagnosis of acute dengue virus infection using NS1 antigen detection in human serum. Neglected Trop Dis, v. 8, p. 1-9, 2008

6. FABRE, A. R. et al. Evaluación sobre infección por virus dengue en la provincia del Chaco (Argentina). Bol Inst Med Reg, p. 132-6, 2004.

7. FORATTINI, O. P. Culicidologia médica: identificação, biologia, epidemiologia. v. 2. São Paulo: EDUSP, 2002.

8. FORATTINI, O. P.; BRITO, M. Reservatórios domiciliares de água e controle do Aedes aegypti. Revista de Saúde Pública, v. 37, n. 5, p. 676-7, 2003.

9. GÁSCON, T. M. et al. Perfil socioeconômico do paciente atendido pelo Laboratório de Análises Clínicas da Faculdade de Medicina do ABC. Arq Med ABC, v. 29, n. 2, p. 111-6, 2004.

10. LEFEVRE, A. M. C. et al. Representações dos agentes de combate ao Aedes aegypti sobre a estratégia de retirada do inseticida nas ações de controle do vetor. Revista Brasileira de Epidemiologia, v. 6, n. 4, p. 359-72, 2003.

11. LIMA, V. L. C. et al. Dengue: inquérito populacional para pesquisa de anticorpos e vigilância virológica no município de Campinas, São Paulo, Brasil. Caderno de Saúde Pública, Rio de Janeiro, v. 23, n. 3, p. 669-80, 2007.

12. MALAVIGE, G. N. et al. Dengue viral infections. Postgrad Med J, n. 80, p. 588-601, 2004.

13. MARZOCHI, K. B. F. Dengue endêmico: o desafio das estratégias de vigilância. Rev Soc Bras Med Trop, v. 37, n. 5, p. 413-5, 2004.
14. MATTAR, S.; PARRA, M.; TORRES, J. Limitaciones para el serodiagnóstico del virus del oeste del Nilo en zonas endémicas con co-circulación de Flavivirus en el Caribe colombiano/Limitations to West Nile Virus serodiagnosis in endemic zones with co-circulation of Flavivirus in the Colombian Caribbean coast. Colomb Med, v. 36, n. 3, p.179-85, 2005.

15. MIAGOSTOVICH, M. P. The evaluation of IgM anti-dengue immune response in sequential infection. Virus Rev \& Research, v. 6, p. 13-9, 2001.

16. PASSOS, M. N. P. et al. Diferenças clínicas observadas em pacientes com dengue causadas por diferentes sorotipos na epidemia de 2001/2002, ocorrida no município do Rio de Janeiro. Rev Soc Bras Med Trop, v. 37, n. 4, p. 293-5, 2004.

17. PONTES, R. J. S.; NETTO, A. R. Dengue em localidade urbana da região sudeste do Brasil: aspectos epidemiológicos. Revista de Saúde Publica, v. 28, n. 3, p. 218-27, 1994.

18. SILVA, L. J.; RICHTMANN, R. Vacinas em desenvolvimento: estreptococo do grupo $\mathrm{B}$, herpes-zóster, HIV, malária e dengue. Jornal de Pediatria, Rio de Janeiro, v. 82, n. 3 , p. 115-24, 2006.

19. STEPHENSON, J. R. Understanding dengue pathogenesis: implications for vaccine design. Bull World Health Organ, n. 83, p. 308-14, 2005.

20. SUPERINTENDÊNCIA de Controle de Endemias (SUCEN). Secretaria de Estado da Saúde. Principais problemas na normatização das atividades de vigilância e controle do Aedes aegypti e ajustes necessários. São Paulo, 2000.

21. TEIXEIRA, M. G. et al. Dengue: twenty-five years since reemergence in Brazil. Cad Saúde Pública, Supl. 1, p. S7-S18, 2009.

22. VASCONCELOS, P. F. C. et al. Epidemia de febre clássica de dengue causada pelo sorotipo 2 em Araguaina, Tocantins, Brasil. Rev Inst Med Trop, v. 35, p. 141-8, 1993.

23. WATTHANAWORAWIT, W. et al. A prospective evaluation of diagnostic methodologies for the acute diagnosis of dengue virus infection on the Thailand-Myanmar border. Trans Royal S Trop M Hyg, 2010. 